\title{
http://bjas.journals.ekb.eg \\ Dysregulated Arginine Metabolism and Cardiopulmonary Dysfunction in Patients with Thalassemia
}

S.D.Mohamed, K.A.Eid, H.M.Kamal

Pediatrics and Clinical,Chemical Pathology Dept., Faculty of Medicine, Benha Univ., Benha, Egypt

E-Mail: Eman_126@gmail.com

\begin{abstract}
Pulmonary hypertension $(\mathrm{PH})$ is common in thalassemia and contributes to mortality. Advancing age and a history of splenectomy are major risk factors in this population. The etiology of $\mathrm{PH}$ is multifactorial, involving a complex interaction of platelets, the coagulation system, erythrocytes, and endothelial cells along with inflammatory and vascular mediators. The long-term effect of splenectomy, red cell membrane pathology, coagulation abnormalities, low nitric oxide (NO) bioavailability, excess arginase activity, platelet activation, oxidative stress, iron overload, and chronic hemolysis play a role. The process of hemolysis disables the arginine-NO pathway through the simultaneous release of erythrocyte arginase and cell-free hemoglobin. Both NO and its obligate substrate arginine are rapidly consumed. The biological consequences of hemolysis on NO bioavailability ultimately translate into the clinical manifestations of PH. Guidelines for the management of PH in thalassemia have not yet been established; however, clinical trials are ongoing in an effort to guide future therapy.
\end{abstract}

\section{Introduction}

The thalassemia syndromes are a heterogeneous group of inherited hemoglobin disorders resulting from unbalanced production of the alpha and beta globin subunits of the hemoglobin tetramer [1].

Over 125 different genetic lesions can cause $\beta_{-}-$ thalassemia, which is characterized by decreased $(\beta+-$ thalassemia) or absent (B0-thalassemia) synthesis of the $\beta_{-}$-globin chain. Thalassemia is most common in individuals whose ancestors originated from the Mediterranean region, Africa, southern China, Southeast Asia, and India [2].

The clinical spectrum is a consequence of imbalanced globin chain accumulation, resulting in impaired erythropoiesis and hemolytic anemia. The two clinically significant phenotypes of $\beta_{-}-$ thalassemia have been designated thalassemia major (TM) and thalassemia intermedia (TI).

TM is characterized by severe anemia starting during the first year of life, requiring life-long transfusion therapy for survival, while TI has a later clinical onset with a milder anemia, does not typically require chronic transfusions, and offers a longer life expectancy. Heart failure is the most common cause of death in both forms of the disease [3].

thalassemia heart disease involves mainly left ventricular dysfunction caused by transfusion-induced iron overload. However, recent studies suggest that both TM and TI patients have a unique hemodynamic pattern consistent with right ventricular cardiomyopathy and pulmonary hypertension $(\mathrm{PH})$, in addition to the left ventricular abnormalities [4].

Secondary PH is emerging as a significant cause of mortality and morbidity in patients with hemolytic anemia. It is defined as a mean pulmonary artery pressure of $\geq 25 \mathrm{mmHg}$ at rest or $\geq 30 \mathrm{mmHg}$ during exercise, and can result from a wide range of conditions.

$\mathrm{PH}$ in thalassemia is associated with vasoconstriction, vascular smooth muscle proliferation, and irregular endothelium in pulmonary arteries with associated thrombosis. These conditions all contribute to luminal narrowing, and eventual right ventricular failure [6].

Although overlap in mechanisms contributing to vasculopathy and $\mathrm{PH}$ is expected in all forms of thalassemia, the pathophysiology of $\mathrm{PH}$ is fundamentally different in patients with TI compared to TM. Hemolysis is likely a driving force toward $\mathrm{PH}$ in nontransfused TI patients, while the consequences of iron overload and oxidative stress play a more significant role in TM patients on transfusion therapy [8].

There is growing evidence that $\mathrm{PH}$ is a disease process that involves altered arginine metabolism or decreased bioavailabilityAs in thalassemia we found dysregulated arginine metabolism [10].

Low global arginine bioavailability, associated with mortality in thalassemia [11] has recently been prospectively linked to increased cardiovascular risk, coronary artery disease, and adverse cardiovascular events including death, myocardial infarction, and stroke in over 1,000 patients undergoing elective cardiac catheterization [12] This supports a more extensive role for arginine bioavailability in the pathogenesis of vasculopathy independent of genotype. High concentrations of the arginineconsuming enzyme arginase are found in the erythrocytes of thalassemia patients [13].

\section{Aim of the work}

The aim of this study is to evaluate the role of arginine in thalassemia patients and its relation to cardiopulmonary dysfunction mainly pulmonary hypertension through echo examination and correlation of these results with the severity of the case of thalassemia with transfusion pattern.

\section{Subject and Method}

- This prospective, randomized controlled study has been done on 50 patients with $\beta$-thalassemia, Age of patients from 6 months to 18 years excluding Other chronic hemolytic anemia, Congenital or rheumatic heart disease, Other systemic diseases and 20 healthy control child, at outpatient's pediatric Hematology \& Oncology unit, Benha children 
hospital, over 12 months duration

All children ( patients \& control ) subjected to the following:

Complete history taking, Full clinical examination, Complete blood count, Reticulocytic count., Liver enzymes (AST \& ALT), Kidney function tests (urea \& creatinine), Serum Ferritin, Plasma arginine level by ELISA.

\section{Echo Doppler}

Subjects were screened for $\mathrm{PH}$ by echocardiography performed at steady-state, defined as; $\geq 2$ weeks from an acute illness including febrile illness, or hospital echocardiography, Pulmonary artery systolic pressure (PASP) was computed as the sum of transtricuspid gradient and the right atrial pressure.

Table( 1) Etiology and risk factors for pulmonary hypertension in thalassemia

\begin{tabular}{l}
\hline Advancing age \\
\hline Splenectomy \\
Hemolysis \\
Oxidative stress \\
Iron overload \\
Chronic inflammation \\
Hypercoagulable state \\
Hypoxemia \\
Red blood cell membrane \\
alterations \\
Low nitric oxide bioavailability \\
Arginine dysregulation \\
Arginase excess \\
splenectomy, .(9)
\end{tabular}

\section{Results}

\section{Subject characteristics}

- Fifty patients with thalassemia syndrome were included in this study. $78 \%$ of patients are TM the rest are TI .

\section{Cardiopulmonary evaluations}

- Tricuspid regurge velocity (TRV) is significantly higher in patient group ranging from $2.4-3.4 \mathrm{~m} / \mathrm{s}$ with median 2.65 than control group which range from 0.5-2.1 with median 0.9

- Pulmonary artery pressure PAP is significantly higher in patient group than control group. With percentage of $60 \% \operatorname{mild}(25-35) \mathrm{mmHg}, 38 \%$ moderate (35-60)mmHg and $2 \%$ severe (>60)mmHg

- There is high significant $(\mathrm{P}<0.001)$ increase of PAP in splenectomized patients than non splenectomized

\section{Laboratory parameters}

there is highly significant $(\mathrm{P}<0.001)$ decrease of plasma arginine in thalassemic patients ranging 11-76 with SD \pm 18.04 than control group ranging 80-121 with $\mathrm{SD} \pm 11.61$

Also there is highly significant negative correlation in thalassemic patients between each of age, serum ferretin, platelet count, tricuspid valve velocity and pulmonary artery pressure with plasma arginine and there is positive significant correlation between pretransfusion hemoglobin and plasma arginine

In our study we find that there was significant decrease of plasma arginine in patients with $\beta$ thalassemia major than $\beta$ thalassemia intermedia $(\mathrm{P}<0.79)$ and both types of patients have highly significant decrease in plasma arginine than control group $(\mathrm{P}<0.001)$

Also there is high significant decrease in plasma arginin in patients with ECG changes ranging 11-28 with SD \pm 5.1 while plasma arginin in patients without ECG abnormalities ranging 23-76 with $\mathrm{SD} \pm 13.9$

As mentioned before there is high significant decrease of plasma arginin in splenectomized patients than those having their spleen intact, as plasma arginin in patients with splenectomy range 11-23, SD \pm 4.08 while patients with no history of splenectomy range is $23-76, \mathrm{SD} \pm 13.7(\mathrm{P}<0.001)$.

\section{Discussion}

Our study revealed Decrease plasma arginine in patient group with negative correlation between it and PAP \& TRV, this result was consistent with the study carried by [14] which demonstrated that there was decrease level plasma arginin in patients with hemolysis associated complication as right ventricular dysfunction, pulmonary hypertension and high TRV

Of interest [15] published an association of TRV elevation \& $\mathrm{PH}$ with reduced plasma arginine, together with increased anaemia

there was highly significant decrease of plasma arginine in patients with $\beta$ thalassemia major compared to $\beta$ thalassemia intermedia and both types of patients are highly significant decrease in plasma arginine than control group it was consistent with study carried by [16][17] who demonstrated significant decrease of plasma arginin with increase rate of hemolysis as in thalassemia major patient

in our study There was highly significant increase in TRV ranging from $2.4-3.4 \mathrm{~m} / \mathrm{sec}$ in thalassemic patients than control group which ranging from $0.5-2.1$ 
$\mathrm{m} / \mathrm{sec}$, also high significant increase in PAP in thalassemic patient ranging from $26-65 \mathrm{mmHg}$ than control group ranging from $15-24 \mathrm{mmHg}$ which was proved with number of studies as $[18,19]$.

while there was non significant difference in PAP \& TRV between thalassemia major and thalassemia intermedia patients which was in agreement with study done [20] which proved that patients with thalassemia major not at increased risk for PH or increase TRV than patients with thalassemia intermedia

In our study advancing age of thalassemic patients, and history of splenectomy has increase risk of $\mathrm{PH}$, elevated TRV and decrease plasma arginin which agreed with number of studies [21,22] which demonstrate that Advancing age and a history of splenectomy are major risk factors for $\mathrm{PH}$ in this population

Also our study was ongoing with [23] who demonstrated that surgical splenectomy in chronic hemolytic disorders has been associated with increased prevalence of thromboembolic disease and $\mathrm{PH}$ due to combination of hypercoagulability, platelet activation, thrombocytosis and disturbance in endothelial function but $[24,25]$ was against our study by finding that there was no relation between splenectomy with $\mathrm{PH}$ and TRV.

our study demonstrate that serum ferritin had high significant positive correlation with $\mathrm{PH} \& \mathrm{TRV}$ as proved by $[26,27]$ while In one study of patients with $\mathrm{TM}$, the degree of anemia, number of transfusions, and serum ferriten levels did not appear to correlate with risk of PH [28].

splenectomy associated with highly significant decrease in plasma arginin in thalassemic patients , this study was in agreement with data published by [29] which demonstrated that endothelial and vascular injury that occur after splenectomy result in depletion of plasma arginine.

\section{Conclusions}

Coagulation abnormalities, haemolysis and arginine dysregulation emerged as major mechanisms associated with an elevated TRV in this cohort of thalassaemia patients. An altered arginine metabolome has been implicated in the pathophysiology $\mathrm{PH}$ in a number of settings .

These data provide additional support for its role in PH-risk in thalassaemia. Nearly all human cell-types contain arginase, an intracellular enzyme released into circulation upon cell damage or cell death, but the greatest source of arginine dysregulation in haemoglobinopathies is erythrocyte- derived arginaseI released during haemolysis, Although the sources and specific enzyme isoforms remain to be identified in $\beta$-thalassaemia, it is intriguing that arginase activity and concentration correlated so strongly to echocardiographic and cardiopulmonary dysfunction,

It is possible that this may exist commonly in other myocardial disorders, particularly those associated with low plasma arginin and may provide a novel area to pursue therapeutically. This study provides further evidence that arginine dysregulation may contribute to cardiopulmonary dysfunction in $\beta$-thalassaemia. Arginase inhibition or interventions aimed at restoration of 1-arginin may hold promise for haemolytic disorders. These data may establish novel directions for future research in the thalassaemia syndromes and beyond. in other myocardial disorders, particularly those associated with low plasma arginin and may provide a novel area to pursue therapeutically. This study provides further evidence that arginine dysregulation may contribute to cardiopulmonary dysfunction in $\beta$-thalassaemia. Arginase inhibition or interventions aimed at restoration of GAB may hold promise for hae.

\section{Reference}

[1] L.Kautz, G.Jung, X.Du, Erythroferrone contributes to hepcidin suppression and iron overload in a mouse model of beta-thalassemia. Blood, Vol.126, PP.2031-2037, 2018

[2] R.Origa, M.Cazzola, E.Mereu, Differences in the erythropoiesis-hepcidin-iron store axis between hemoglobin $\mathrm{H}$ disease and beta thalassemia intermedia. Haematologica, Vol.100, PP. 169$171,2017$.

[3] A.Piga, S.Perrotta, A.Melpignano, Luspatercept decreases transfusion burden and liver iron concentration in regularly transfused children with beta-thalassemia. 21st Congress of the European Haematology Association. Copenhagen, Denmark, Vol.16, PP.251-257, 2016

[4] M.D.Cappellini,J.B.Porter, V.Viprakasit, A.T.Ta her,Elsevier Correction of hypercoagulability and amelioration of pulmonary arterial hypertension by chronic blood transfusion in an asplenic hemoglobin E/beta-thalassemia patient - Blood reviews, Vol.25, PP.2844-2846, 2018.

[5] A.T.Taher, D.J.Weatherall, M.D.Cappellini, The Lancet, 2018 ßeta-thalassaemia causes defective haemoglobin synthesis leading to ineffective erythropoiesis, chronic haemolytic anaemia, and subsequent clinical complications. Blood transfusion and iron chelation allow long-term disease control, and haematopoietic stem cell, Vol.63, PP.254-256, 2018.

[6] G.G. Gan, Y.L. Hue, J. SatharFactors affecting quality of life in patients with thalassaemia major and intermedia Ann Acad Med Singapore, Vol.45, PP.452-456, 2016.

[7] N. Dhirar, J. Khandekar, D. Bachani, D. MahtoT halassemia major,how do we improve quality of life? Springerplus, Vol.5, PP. 1895-1899,2016

[8] D.J. Pennell, J.B. Porter, A. Piga, Y.R. Lai, A. El -Beshlawy, M. Elalfy, Sustained improvements in myocardial $\mathrm{T} 2 *$ over 2 years in severely ironoverloaded patients with beta thalassemia major 
treated with deferasirox or deferoxamine Am J Hematol, Vol.90 , PP. 91-96,2015.

[9] C. Casu, V. Lo.Presti, P.R. Oikonomidou, L. Mel chiori, O. Abdulmalik, P. Ramos, Short-term administration of JAK2 inhibitors reduces splenomegaly in mouse models of ss-thalassemia intermedia and major Haematologica, Vol.103, PP. 46-49,2018.

[10] L.Godinas, E.M.Lau, D.Chemla, Diagnostic concordance of different criteria for exercise pulmonary hypertension in subjects with normal resting pulmonary artery pressure. Eur Respir J, Vol.48, PP.254-257,2016.

[11] B.A.Maron, E.L.Brittain, G.Choudhary, M.T.Gladwin, Redefining pulmonary hypertension. Lancet Respir , Vol.6, PP.168$170,2018$.

[12] N.Arbaiy, S.E. Sulaiman, N.Hassan, Z.A.Afip,Integrated Knowledge Based Expert System for Disease Diagnosis System. IOP Conference Series: Materials Science and Engineering, Vol.226, PP. 258-262, 2017.

[13] O.Papakonstantinou, E.E. Drakonaki, T.Maris, A.Vasiliadou , A.Papadakis, N.Gourtsoyiannis,MR imaging of spleen in beta-thalassemia major. Abdominal imaging. , Vol.40(7), PP.2777-82, 2015.

[14] K.M.Salama, O.M.Ibrahim, A.M.Kaddah, S.Boseila, L.A.Ismail , M.M.A.Hamid, Liver enzymes in children with beta- thalassemia major: Correlation with iron overload and viral hepatitis. Open Access Macedonian Journal of Medical Sciences, Vol.3(2), PP.287289, 2015.

[15] N.F.M.Yatim , M.A.Rahim , K.Menon , F.M.Al-Hassan ， R.Ahmad, A.B.Manocha, Molecular Characterization of $\alpha$-and $\beta$ Thalassaemia among Malay Patients. International journal of molecular sciences, Vol.15(5), PP.8835-45, 2014.

[16] Olga.Rafikova, Imad.Al Ghouleh, Ruslan.Rafikov, Focus on early events: pathogenesis of pulmonary arterial hypertension development, Vol.62(1), PP.48-45, 2019.

[17] B.A.Maron, S.H.Abman,Translational advances in the field of pulmonary hypertension: focusing on developmental origins and disease inception for the prevention of pulmonary hypertension. Am J Respir Crit Care Med, Vol.195, PP.292-301, 2017.

[18] K.Takahashi, H.Taniguchi, M.Ando, K.Sakamoto, Y.Kondoh, N.Watanabe, T.Kimura, K.Kataoka, A.Suzuki, S.Ito, Y. Hasegawa,Mean pulmonary arterial pressure as a prognostic indicator in connective tissue disease associated with interstitial lung disease: a retrospective cohort study. BMC Pulm Med, Vol.16, PP.55,2016.

[19] C.D.Cappellini, E.Grespi, E.Cassinerio, Coagulation and splenectomy: an overview. Ann N Y Acad Sci;Vol.1054,PP.317-24,2015.

[20] L.J.Haywood,Cardiovascular Function and Dysfunction in thalassemia. J Natl Med Assoc, Vol. 101, PP.24-30, 2019.

[21] Lin EE, M.T.Gladwin \&R.F.Machado,Pulmonary hypertension in patients with hemoglobinopathies: could a mechanism for dysfunction provide an avenue for novel therapeutics? haematologica, Vol.90, PP.441-44, 2015.

[22] F.D.Pashankar, J.Carbonella, A.B.Asaad, Prevalence and Risk Factors of Elevated Pulmonary Artery Pressures in Children With thalassemia, Pediatrics, Vol.121, PP.777-82, 2018.

[23] Black SM, E.Mata-Greenwood, R.W.Dettman, Emergence of smooth muscle cell endothelin Bmediated vasoconstriction in lambs with experimental congenital heart disease and increased pulmonary blood flow. Circulation, Vol.108, PP.1646-54, 2013.

[24] S.Ahmed, A.K.Siddiqui, A.Sadiq, Echocardiographic abnormalities in sickle cell disease. Am J Hematol, Vol.76, PP.195-98, 2004.

[25] J.A.Talano, C.A.Hillery, J.L.Gottschall, Delayed hemolytic transfusion reaction/hyperhemolysis syndrome in children with sickle cell disease. Pediatrics, Vol.111, PP. 661-65, 2013.

[26] A.Meloni, J.Detterich, A.Pepe, P.Harmatz, T.D.Coates, \& J.C. Woods, Pulmonary hypertension in well-transfused thalassemia major patients. Blood Cells, Molecules, \& Diseases, Vol.54, PP.189-194, 2015.

[27] Voskaridou E, G.Tsetsos, A.Tsoutsias, Pulmonary hypertension in patients with sickle cell/ b thalassemia: incidence and correlation with serum $\mathrm{N}$-terminal pro-brain natriuretic peptide concentrations. Haematologica, Vol.92, PP.738-43, 2007.

[28] R.F.Machado, S.E.Martyr, A.Anthi, Pulmonary Hypertension in Sickle Cell Disease: Cardiopulmonary Evaluation and Response to Chronic Phosphodiesterase 5 Inhibitor Therapy. Blood (ASH Annual Meeting Abstracts), Vol.104, PP. 235-238, 2004. 